\title{
SOLVENT EFFECT ON ZERO-VALENT IRON NANOPARTICLES (nZVI) PREPARATION AND ITS THERMAL OXIDATION CHARACTERISTIC
}

\author{
Patiparn Boonruam ${ }^{1,2}$, Soipatta Soisuwan ${ }^{1,2}$, Piyachat Wattanachai', \\ Héctor Morillas ${ }^{3}$, and Settakorn Upasen ${ }^{1,2}$ \\ ${ }^{1}$ Department of Chemical Engineering, Engineering Faculty, Burapha University, Chonburi, Thailand, Thailand, \\ Tel: +6638102222, e-mail: settakorn@eng.buu.ac.th \\ ${ }^{2}$ Research Unit of Developing Technology and Innovation of Alternative Energy for Industries, Burapha University, \\ Chonburi, Thailand, Tel: +6638102222, e-mail: settakorn@eng.buu.ac.th \\ ${ }^{3}$ Department of Analytical Chemistry, Faculty of Science and Technology, University of the Basque Country \\ (UPV/EHU), Bilbao, Basque Country, Spain, Tel: +34946015551, e-mail: hector.morillas@ehu.eus
}

Received Date: September 24, 2019; Revised Date: March 10, 2020; Acceptance Date: March 23, 2020

\begin{abstract}
Zero-valent iron (ZVI) nanoparticle exists a nanoscale $(1-100 \mathrm{~nm})$ of the iron particle with zero oxidation number. It has acquired considerable attention for its potential to capture the free-electron moieties. The production and storage of ZVI material, however, is challenging because it is relatively unstable. In this research, we aim to study of solvent effects on ZVI preparation and its characterization. The nano-scaled ZVI was synthesized by a chemical reduction method. Iron (III) chloride hexahydrate $\left(\mathrm{FeCl}_{3} \cdot 6 \mathrm{H}_{2} \mathrm{O}\right)$ was used as a chemical precursor and sodium borohydride solution $\left(\mathrm{NaBH}_{4}\right)$ as a reducing agent. Two parameters used in this study were: i) solvent types (ethanol, diethyl ether, and acetone) ii) proportion of solvent and deionized water (4:0, 4:1, and $4: 2$ by volume). We characterized the physical and chemical properties of the synthesized samples (e.g. particle size and distribution, morphology, and the chemical composition) using various techniques, for example, TEM, UV-Vis spectrophotometer, and XRD. Moreover, we performed a thermal oxidation reaction of synthesized powder samples using DSC and TGA tools. The results show that the nZVI particle formed a spherical shape with the smallest particle size of $\sim 39 \mathrm{~nm}$. The solvent type was the key parameter protecting the oxidation reaction during the synthesis process. According to the spherical shape of the synthesized nZVI samples, an estimated specific surface area was also reported. The cubic structure of nZVI particles was estimated at 79-81 wt.\%, and almost 20 wt. $\%$ was attributed to iron oxide $\left(\mathrm{Fe}_{2} \mathrm{O}_{3}\right)$ cubic phase. The oxidation reaction occurred above $400^{\circ} \mathrm{C}$. The minimum enthalpy of thermal oxidation was approximately $1600 \mathrm{~J} / \mathrm{g}$. Furthermore, the relation between thermal oxidation enthalpy and nZVI particle sizes were revealed and predicted by the Boltzmann equation.
\end{abstract}

Keywords: Characterization, nZVI, Oxidation, Solvent, Synthesis, Thermal

\section{Introduction}

The zero-valent ion nanoparticles are ultrafine particles in the size of a nanometer with a high specific surface area. It has been promoted to be an excellent material and employed for several applications including environmental purification [1,2], bio/chemical sensors [3], catalysts [4, 5], food packaging [6]. To obtain the metallic particles in nanometer size, generally, there are two methods, namely "top-down" and "bottom-up." The top-down methods, such as mechanical 
grinding of bulk metals, have difficulty in producing narrow particle size distribution [7]. On the other hand, the bottom-up methods deliver an appropriate narrow particle-size distribution. This technique initiates from atomic/molecular precursors in either gas or solution phase building up nucleate, and these nuclei begin to glow until they form a nanoparticle slowly. The nanoparticle forms different structures, shapes, and sizes due to kinetics parameters such as temperature, stabilizing agent types, and concentrations.

Over the last decades, manufactured nanoparticles (MNPs) for zero-valent iron are produced by bottom-up methods, including precipitation [1], hydrogenation [7], or chemical reduction [8]. The most widely used method for environmental purposes is the reduction of Fe(II) or Fe(III) cations solution using borohydride anion, as shown in the following reaction eq. 1 [8].

$$
2 \mathrm{FeCl}_{3}+6 \mathrm{NaBH}_{4}+18 \mathrm{H}_{2} \mathrm{O} \rightarrow 2 \mathrm{Fe}^{0}+6 \mathrm{NaCl}+6 \mathrm{~B}(\mathrm{OH})_{3}+21 \mathrm{H}_{2}
$$

A selection of aqueous media type plays an important role in keeping iron in its zerovalent forms. In general, the nZVI particle forms a structure of core-shell - core is mainly composed of zero-valent iron, and the shell is combined oxides such as $\mathrm{F}_{3} \mathrm{O}_{4}, \mathrm{Fe}_{2} \mathrm{O}_{3}$, and $\mathrm{FeOOH}$ [9]. Such metallic iron efficiently acts as an electron donor and forms mixed oxide/hydroxide shell; it impacts on the nZVI characteristics such as morphologies, the charge of surface, and the composition of bulk. These fundamental properties consequently affected magnetic characteristics, aggregation tendency, surface oxidation, and reaction with the environment.

In different applications, the iron metal can react with oxygen carriers, and it oxidizes to form a sub-oxide shell. With this oxidation reaction, the heat generation rate can be expected to be very high, specifically for the ultra-small particle [10]. Many researchers have studied the kinetics of oxidation reaction of metal films introduced to oxygen gas at low temperatures [11, 12], metallic nanoparticle oxidation [13], oxidation of bulk iron by oxygen and water vapor [1, 10, 14]. The oxidation reaction of iron nanoparticle occurred sequentially - first, oxidizing the iron core into the disordered phase formation as well as crystalline iron oxides, secondly partial-oxidation of $\mathrm{Fe}_{3} \mathrm{O}_{4}$ into an $\alpha-\mathrm{Fe}_{2} \mathrm{O}_{3}$ structure, and lastly, full-oxidation of $\mathrm{Fe}_{3} \mathrm{O}_{4}$ and iron core to $\alpha-\mathrm{Fe}_{2} \mathrm{O}_{3}$ phase. Furthermore, the studies suggest that the amount of heat reaction may occur differently when the iron metal is in distinct nanoparticle geometry, size, and shape - a thorough comprehension of the oxidation reaction of different nanoscale particle size at high temperature should be addressed.

This study aims to produce the nano-scaled ZVI particles by a facile chemical reduction method. Different solvent types and quantity of DI water are studied to prevent heavy oxidation during the synthesis process and to characterize the synthesized nZVI particles in terms of various properties such as morphology, size, surface area, chemical structure, and chemical composition. Finally, the size-dependent heat release in the thermal oxidation reaction is also discussed.

\section{Experimental}

\section{Chemicals}

All chemicals employed in this study were analytical reagent (AR) grade. They were purchased from several enterprise suppliers. The refinement process of all chemicals is not required before handling 


\section{Synthesis}

ZVI nanoparticles were synthesized using a facile chemical reduction method under atmospheric conditions as described elsewhere $[8,15]$. The type of media reagent is the key factor related to the particle size as well as preventing oxidation reaction during the synthesis process. Three media reagent types, such as ethanol $\left(\mathrm{C}_{2} \mathrm{H}_{5} \mathrm{OH}\right)$, diethyl ether $\left(\left(\mathrm{C}_{2} \mathrm{H}_{5}\right)_{2} \mathrm{O}\right)$, and acetone $\left(\mathrm{C}_{3} \mathrm{H}_{6} \mathrm{O}\right)(\mathrm{P} \& \mathrm{~N}$ Hitech chemical, LTD) were chosen. Figure 1 illustrates a step of nZVI synthesis by $\mathrm{NaBH}_{4}$ reduction method. A flat flask reactor with two open necks was filled with a mixture of ethanol (the first media reagent) and deionized (DI) water in $4: 1$ by volume. A $0.5406 \mathrm{~g} \mathrm{FeCl} 3.6 \mathrm{H}_{2} \mathrm{O}$ (Sigma-Aldrich) was consequently added and stirred well for 10 minutes. The reducing agent of $0.1 \mathrm{M} \mathrm{NaBH}_{4}$ in $100 \mathrm{~mL}$ deionized water $(0.3785 \mathrm{~g})$ was slowly dropped into the mixture solution. The solution turned into black color. After completely adding the reducing agent, the colloidal suspended solution was continuously stirred for 10 minutes. The black color particles were separated from the liquid phase using the centrifugation technique. Then, washing under atmospheric conditions was done for several times using absolute ethanol (or the same media reagent). The washing process is one of the vital steps because it protects the rapid oxidation of nZVI. Finally, the synthesized particles were dried in a vacuum oven at $105^{\circ} \mathrm{C}$ for 12 hours. The volumetric ratio of 4:0 and 4:2 of media reagent and DI water was varied. The procedure of nZVI synthesis for the other two media reagents, diethyl ether and acetone, was performed as the same protocol as the ethanol one illustrating in Figure 1.

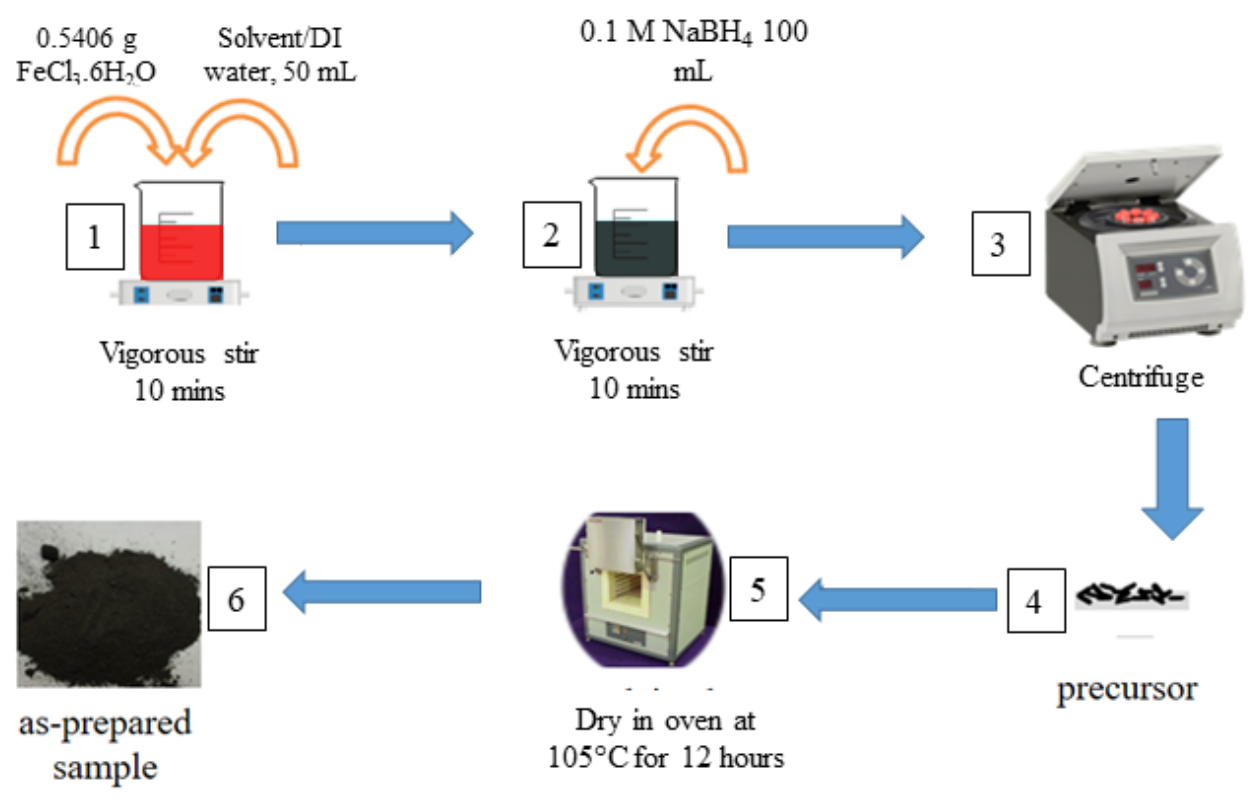

Figure 1. A protocol of simple nZVI synthesis experiment by chemical reduction method using $\mathrm{NaBH}_{4}$ reducing agent

\section{Characterization}

\section{$X$-ray Diffraction}

The X-ray powder diffraction (XRD) analysis was done using Bruker D8ADVANCE X-ray diffractometer (Chulalongkorn University, Thailand). The operating wavelength was at $1.54056 \AA$ A a high-density $\mathrm{Cu}-\mathrm{K} \alpha$ radiation. We recorded the XRD pattern over an angular range 
(20) of 10-80 degrees, and an increment step of $0.5 \mathrm{sec} / \mathrm{step}$. Additionally, apart from the XRD analyses, a semiquantitative estimation of the phase composition based on a weight percentage (wt.\%) was also carried out using Maud XRD software, and the references of XRD database were taken from Crystallography open source library.

\section{TEM Analysis}

Morphology characteristics of synthesized nZVI samples were performed using the transmission electron microscope (TEM) with the Phillip-Tecnai20 model (Burapha University, Chonburi, Thailand). The characterization was done with a potential of $100 \mathrm{kV}$ and $13,5000 \mathrm{x}-13,000 \mathrm{x}$ resolution. In order to prepare a well-dispersed particle of the analyzed sample, we dissolved the nZVI powders using absolute ethanol, and the suspension solution was well sonicated for several minutes.

\section{Thermal Analysis}

Thermogravimetric analysis for the synthesized nZVI samples was done using the TGA/DSC3+ of Mettler Toledo (Bangkok, Thailand). The DSC technique is used to quantify the heat of oxidation reaction. The TGA/DSC curves were achieved at a temperature range of $30-700^{\circ} \mathrm{C}$ under the flow rate of $25 \mathrm{~mL} / \mathrm{min}$ pure oxygen. The increment of heating value was set at $10{ }^{\circ} \mathrm{C} / \mathrm{min}$.

\section{Results and Discussion}

\section{Morphological Characteristics}

Morphology characteristic of synthesized samples was analyzed by transmission electron microscope with 55,000x-250,000x resolution. The representative TEM images of each sample are shown in Figure 2. The synthesized ZVI nanoparticles for ethanol and diethyl ether solvent were a sphere and/or a quasi-sphere shape. The sphere nZVI particles, for example, E-2 sample (see in Figure 2), appeared clearly with two layers - the iron core layer covered by a thin shell layer. In order to analyze the actual nZVI particle size, only the core size was measured. The particle size for the ethanol solvent samples was smaller than the one prepared by diethyl ether solvent. For the use of ethanol solvent (E-1, E-2, E-3 sample), the smallest particle size was approximately $39 \mathrm{~nm}$ (E-1 or pure ethanol sample). However, adding an amount of DI water influenced the nZVI particle growth. In the case of pure diethyl ether solvent, the nZVI particle sample has the biggest size of $\sim 101 \mathrm{~nm}$ on average. Diluted diethyl ether solution allowed a formation of small nucleate nZVI. Adding DI water at an appropriate level, for instance, 20 vol.\% (see Figure 2 E-2 and D-2) resulted in a significant particle size distribution narrowing the distribution curve of particle size. The solubility of the $\mathrm{FeCl}_{3} .6 \mathrm{H}_{2} \mathrm{O}$ precursor depends on solvent types, and it becomes one of the primary roles to produce nanoscale particles with the proper dispersion. In order to estimate the specific surface area $\left(\mathrm{m}^{2} / \mathrm{g}\right)$, the ratio between surface area

$\left(\pi \mathrm{d}^{2}\right)$ and volume $\left(\pi \mathrm{d}^{3} / 6\right)$ of the sphere was applied and derived, as illustrated in the following equation.

$$
\text { Specific surface area }(\mathrm{SSA})=\frac{6}{d_{T E M} \cdot \rho_{t h}}
$$


where $\mathrm{d}_{\text {TEM }}$ is particle diameter $(\mathrm{nm})$ measured by the TEM instrument and $\rho_{\text {th }}$ is the theoretical density of zero-valent iron, $7.847 \mathrm{~g} / \mathrm{cm}^{3}$ [15]. The specific surface area of the nZVI sample, as shown in Table 1 were $7-20 \mathrm{~m}^{2} / \mathrm{g}$ approximately. It was inversely proportional to the particle size - the smaller the particle size, the better the specific surface area.

Table 1. Particle Size and Specific Surface Area for Synthesized nZVI Samples

\begin{tabular}{clcccc}
\hline $\begin{array}{c}\text { Sample } \\
\text { Name }\end{array}$ & Reagent & $\begin{array}{c}\text { Reagent: } \\
\text { DI Water } \\
\text { (by vol.) }\end{array}$ & $\begin{array}{c}\text { Average } \\
\text { Particle Size } \\
\text { (nm) }\end{array}$ & $\begin{array}{c}\text { Approx. Specific Surface } \\
\text { Area }\left(\mathbf{m}^{\mathbf{2}} \mathbf{g}\right)\end{array}$ & $\begin{array}{c}\text { Magnetic } \\
\text { property }\end{array}$ \\
\hline E-1 & ethanol & $4: 0$ & $39.53 \pm 21.22$ & 19.34 & strong \\
E-2 & ethanol & $4: 1$ & $51.39 \pm 10.15$ & 14.87 & strong \\
E-3 & ethanol & $4: 2$ & $50.39 \pm 25.69$ & 15.17 & strong \\
D-1 & diethyl ether & $4: 0$ & $101.12 \pm 18.83$ & 7.56 & strong \\
D-2 & diethyl ether & $4: 1$ & $42.70 \pm 10.45$ & 17.90 & strong \\
D-3 & diethyl ether & $4: 2$ & $69.49 \pm 25.69$ & 11.00 & weak \\
\hline
\end{tabular}

Note: the nZVI particles was not successfully prepared using acetone (abbr. A) media reagent.
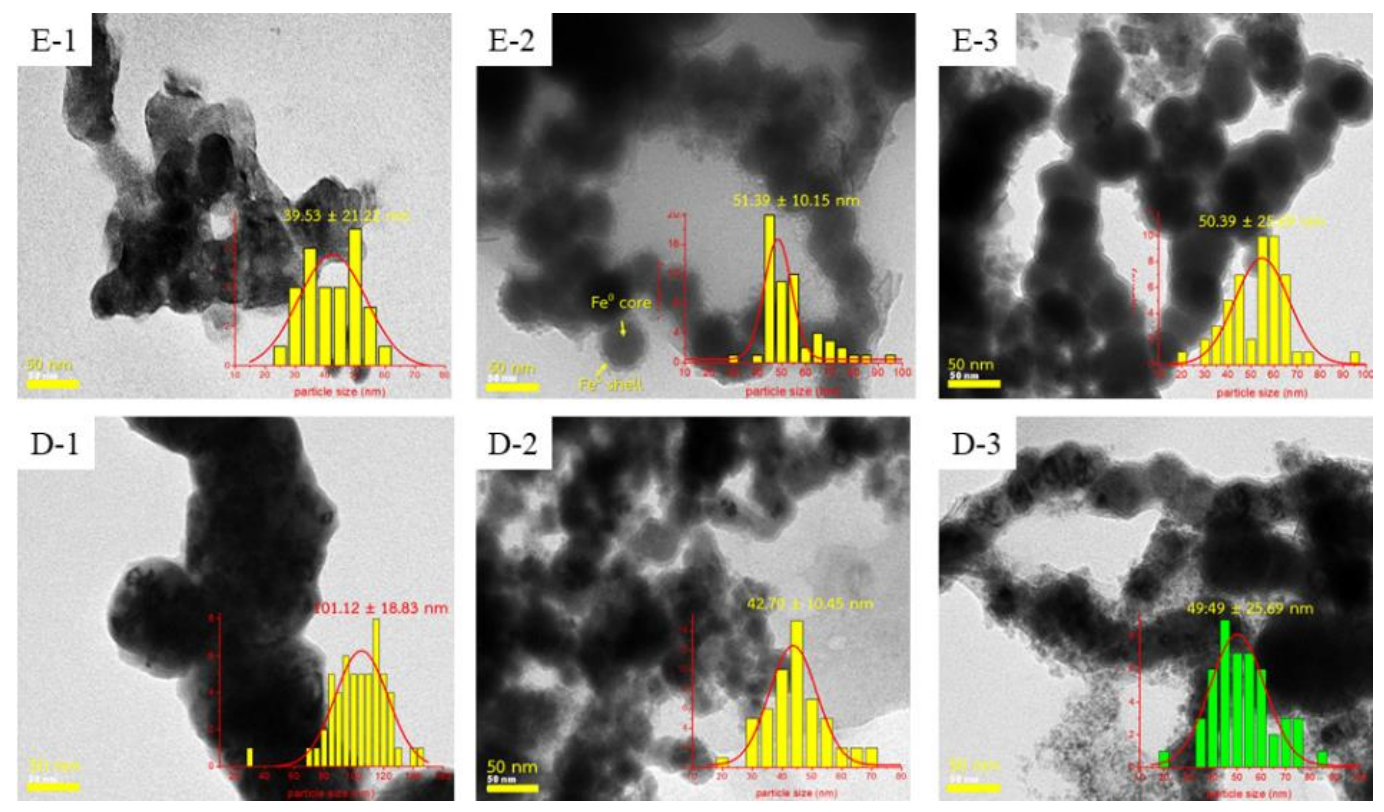

Figure 2. TEM micrograph of synthesized nZVI samples using the different proportion of mixed solvent and DI water [Note: caption of each sample i.e. E-1, E-2, .., D-3 refers to sample name and synthesized solvent described in Table 2]

The nZVI particles possess magnetic properties that depend upon the received history and its physicochemical properties, e.g. article size and shape, composition, and superficial oxidation $[15,16]$. The magnetic property causes a formation of the chain-like structure of the bare nanoparticles as displayed in Figure 2. In this work, the signs of magnetic properties were simply tested by using Neodymium magnetic bar $(50 \times 10 \times 5 \mathrm{~mm})$. The nZVI powder was stored in a ziplocked plastic bag, and the magnetic bar was placed at a few millimeters. The full number of all 
tested nZVI particles attracted by the magnetic bar was considered as strong magnetic signs, while the partially pulled behavior was indicted as weak signs. All the synthesized nZVI samples, except the D-3 sample, resulted in strong magnetic fields. Arancibia-Miranda and co-workers [17] reported the magnetization $\left(M_{s}\right)$ value for bare nZVI particles of about $15 \mathrm{emu} / \mathrm{g}$, and it was increased to $20 \mathrm{emu} / \mathrm{g}$ after the lead absorption process. It was due to the formation of an iron oxide core-shell structure that exhibits ferromagnetic properties and the saturated magnetic of 100 $\mathrm{emu} / \mathrm{g}[15]$.

\section{Chemical Structure and Composition}

The technique of X-ray diffraction was employed to characterize the crystalline nature and phases of all synthesized nZVI samples. Base on the principle of Bragg's Law, the X-ray incident waves are scattered from crystalline lattice planes at a particular angle $(\theta)$. The path-length difference between two waves undergoing interference is equal to $2 \mathrm{~d} \sin \theta$. Note that $\lambda$ is the $\mathrm{X}$-rays wavelength, $n$ is the diffraction order, and $d$ is The distance of separated lattice inter-planar.

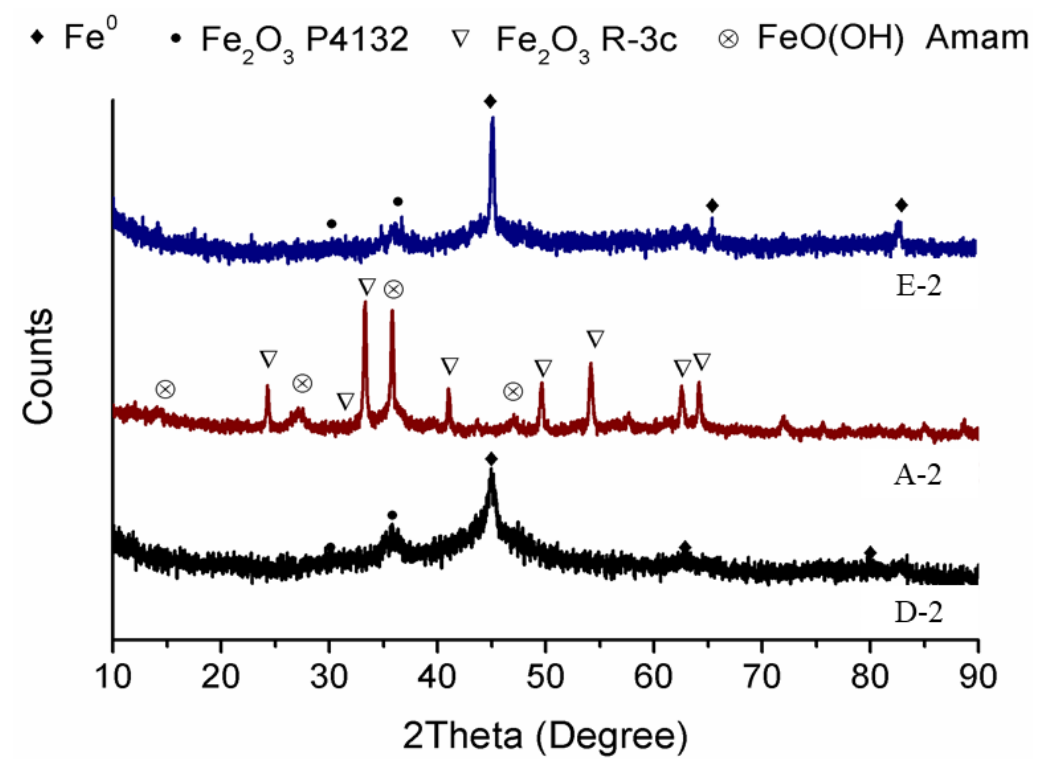

Figure 3. XRD pattern of representative synthesized nZVI samples using 4:1 by volume of solvent and DI water

Figure 3 illustrates the XRD patterns of the representative prepared nZVI powder sample. The XRD patterns for samples prepared by ethanol solution (blue line) and diethyl ether (black line) were similar. It comprises of two chemical compounds; zero-valent iron ( $\mathrm{Fe}^{0}$ ) and iron(III) oxide $\left(\mathrm{Fe}_{2} \mathrm{O}_{3}\right)$. The peaks located at $45^{\circ}, 65^{\circ}$ and $82^{\circ}$ were assigned to the characteristic peak of zero-valent iron $(\alpha-\mathrm{Fe})$ [18]. Comparing to other studies, several researchers observed a similar broad peak at $\sim 4.9^{\circ}$, especially, the one prepared by using diethyl ether. This broad characteristic indicates a disordered structure, amorphous phase [19-21]. The observation of iron (III) oxide was a trace and displayed in a cubic structure with a symmetry group of $\mathrm{P} 4{ }_{13} 32$. The Bragg's peaks were mainly located at $33^{\circ}$ and $35^{\circ}$. The detected $\mathrm{Fe}_{2} \mathrm{O}_{3}$ phase confirmed a thin shell formation which covers $\mathrm{Fe}^{0}$ bulk, as mentioned earlier (Figure 2). Additionally, apart from the XRD analyses, a semiquantitative estimation of the structural composition based on a weight percentage (wt.\%) 
was also carried out. This estimation is based on the intensity (height) of the most intense peak or diffraction maximum of each nZVI or $\mathrm{Fe}_{2} \mathrm{O}_{3}$ phase, and on the RIR (Reference Intensity Ratio) value contained in the files used as database. The semiquantitative estimation of nZVI cubic phases yielded 79-81 wt.\%, and iron oxide $\left(\mathrm{Fe}_{2} \mathrm{O}_{3}\right)$ cubic phase was almost $20 \mathrm{wt} . \%$. It should be noted that the purification and storage process used in this study might be a significant step causing the production of the oxide forms.

For the nZVI sample prepared by acetone solution (Figure 3 red line), the XRD pattern revealed iron (III) oxide $\left(\mathrm{Fe}_{2} \mathrm{O}_{3}\right)$ and ferric oxyhydroxide $(\mathrm{FeO}(\mathrm{OH}))$. The iron particle after the reduction step (see Equation 1) undergoes oxidizing quickly in an acetone solution. It is due to the unstable chemical structure of acetone, which consists of a $\mathrm{C}=\mathrm{O}$ bond - actively donate oxygen to the environment. The observed $\mathrm{Fe}_{2} \mathrm{O}_{3}$ phase exhibited in Rhombohedral structure with a symmetry group of R-3c [22] while the ferric oxyhydroxide, also namely Lepidocrocite, was an orthorhombic phase with Amam symmetry group [23, 24]. Table 2 shows a crystallography summary of representative nZVI samples derived from each solvent type.

Table 2. Crystallography Report of Representative Synthesized nZVI Samples using 4:1 by Volume of Solvent and DI Water

\begin{tabular}{|c|c|c|c|c|c|c|}
\hline \multirow[t]{2}{*}{ Sample } & \multirow{2}{*}{$\begin{array}{l}\text { Chemical } \\
\text { Composition }\end{array}$} & \multirow[t]{2}{*}{ Structural } & \multirow{2}{*}{$\begin{array}{c}\text { Symmetry } \\
\text { Group }\end{array}$} & \multicolumn{3}{|c|}{$\begin{array}{c}\text { Space Lattice } \\
(\AA)\end{array}$} \\
\hline & & & & $\mathbf{a}$ & b & c \\
\hline \multirow{2}{*}{ E-2 } & $\mathrm{Fe}^{0}$ & Cubic & Im-3m & 2.8607 & 2.8607 & 2.8607 \\
\hline & $\mathrm{Fe}_{2} \mathrm{O}_{3}$ & Cubic & $\mathrm{P} 4132$ & 8.3350 & 8.3350 & 8.3350 \\
\hline \multirow{2}{*}{ D-2 } & $\mathrm{Fe}^{0}$ & Cubic & Im-3m & 2.8607 & 2.8607 & 2.8607 \\
\hline & $\mathrm{Fe}_{2} \mathrm{O}_{3}$ & Cubic & $\mathrm{P} 4{ }_{132}$ & 8.3350 & 8.3350 & 8.3350 \\
\hline \multirow{2}{*}{ A-2 } & $\mathrm{Fe}_{2} \mathrm{O}_{3}$ & Rhombohedral & $\mathrm{R}-3 \mathrm{c}$ & 5.0206 & 5.0206 & 13.729 \\
\hline & $\mathrm{FeO}(\mathrm{OH})$ & Orthorhombic & Amam & 3.8600 & 12.500 & 3.0600 \\
\hline
\end{tabular}

\section{Heat of Oxidation}

According to the chemical characteristic results in the previous section, only the nZVI samples prepared by using ethanol and diethyl ether were selected to investigate thermal oxidation properties. The thermal analysis was performed under a fully $\mathrm{O}_{2}$ atmosphere. The TG curves (see in Figure 4) clearly show the first step of weight loss, which was up to $\sim 120^{\circ} \mathrm{C}$, about $5-8$ wt. $\%$ for all investigated samples. It is corresponding to the dehydration of absorbed water on the particle surface and/or hydroxyl group incorporated in the nZVI crystalline structure [25]. Interestingly, for the D-2 sample (see Figure $4 \mathrm{~b}$ blue line), the endothermic peak with $\sim 10 \mathrm{wt} \%$ loss was located at $200-260^{\circ} \mathrm{C}$. It might be due to the breaking down of the hydroxyl group $(-\mathrm{OH})$ for $\mathrm{FeO}(\mathrm{OH})$ composition [26].

The $\mathrm{TG}$ result above $400^{\circ} \mathrm{C}$ for all the samples was in an exothermic profile. It is according to the thermal oxidation, as predicted in Equation 3. The exothermic peak for the sample of ethanol series (Figure 4a) displayed in a different location; E-1 at $480^{\circ} \mathrm{C}(22 \mathrm{wt} . \%)$, E-2 at $410^{\circ} \mathrm{C}(15 \mathrm{wt} . \%)$, and $\mathrm{E}-3$ at $535^{\circ} \mathrm{C}(16 \mathrm{wt} . \%)$. The effect of input $\mathrm{Fe}^{0} / \mathrm{Fe}_{2} \mathrm{O}_{3}$ proportion together with the nZVI particle size were a significant role in the oxidation reaction temperature [27, 28]. In the case of diethyl ether series samples (Figure 4b), the exothermic peak occurred unclear, which is not related to the proportion of added DI water content. Regarding the XRD result, the 
synthesized nZVI powder for diethyl ether solvent seems to have a disordered structure, and it might affect thermal oxidation behavior. Furthermore, the oxidation step of iron nanoparticle occurred in different locations due to the formation of amorphous, distorted as well as crystalline iron oxides [29]. Though these exothermic characteristic curves were unclear, the percent weight curves were gradually increased, especially the D-1 and D-2 samples. The amount of weight gain for each sample resulted not significantly different, about 10-20 wt.\%.

$$
\mathrm{Fe}(s)+\mathrm{Fe}_{2} \mathrm{O}_{3}(s)+\frac{3}{4} \mathrm{O}_{2}(g) \stackrel{\Delta}{\longrightarrow} \frac{3}{2} \mathrm{Fe}_{2} \mathrm{O}_{3}(s)
$$
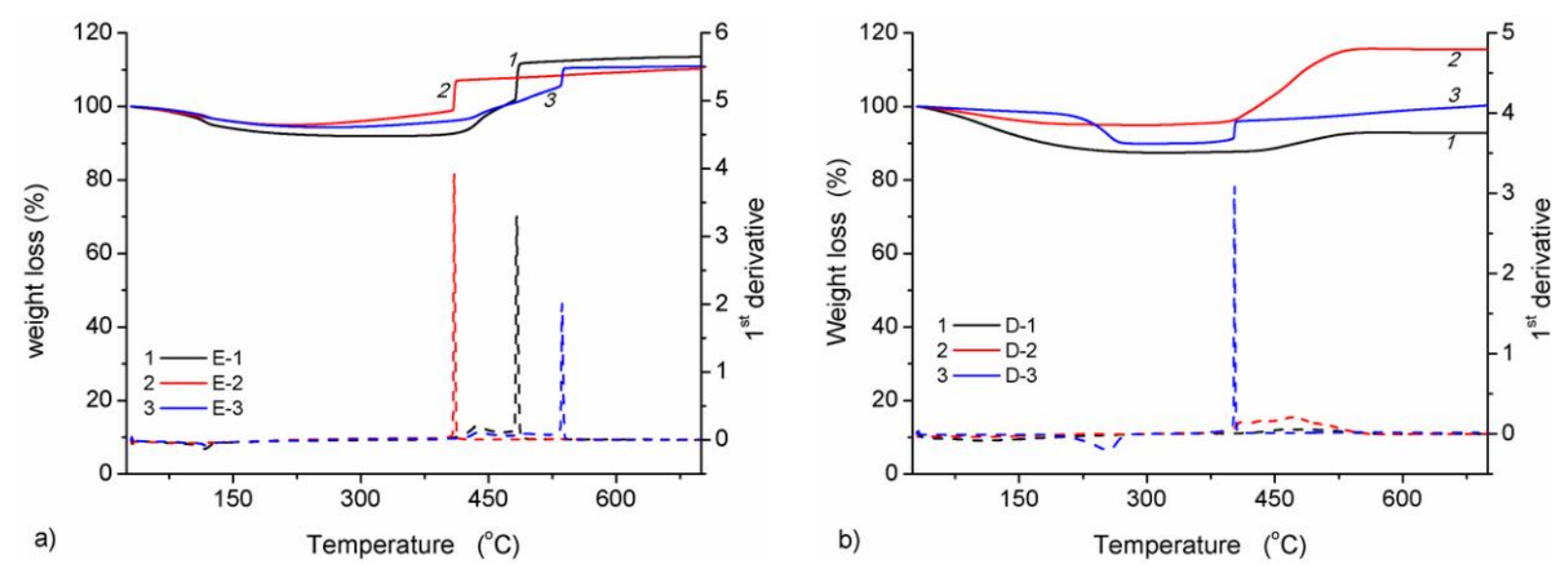

Figure 4. TGA curves and its derivative for synthesized nZVI samples using a) ethanol and b) diethyl ether mixed with DI water in different proportion

The DSC technique also investigated the heat of oxidation reaction for nZVI samples. The enthalpy change $(\Delta \mathrm{H}, \mathrm{J} / \mathrm{g})$ of the oxidation reaction (eq. 3) shows the quantity of heat carried out at constant pressure, it was calculated by the following equation;

$$
\begin{aligned}
& C_{p}=\frac{\text { Heat flow rate }}{\text { Heating rate }}=\frac{q}{\Delta T} \\
& \Delta H=q=\int C_{p} d T
\end{aligned}
$$

where $\mathrm{q}$ is the specific heat $(\mathrm{J} / \mathrm{g}), \mathrm{C}_{\mathrm{p}}$ is the thermal capacity at constant pressure $(\mathrm{J} / \mathrm{g} . \mathrm{K})$, and $\Delta \mathrm{T}$ is rising absolute temperature $(\mathrm{K})$. The heat quantity which released throughout the oxidation at a heating rate of $15{ }^{\circ} \mathrm{C} / \mathrm{min}$ yielded in the rage of $1.6-3.4 \mathrm{~kJ} / \mathrm{g}$. A similar observation was also obtained by the works of Dongsheng Wen and co-workers [30].

The normalized heat amount released from the oxidation reaction was plotted versus nZVI particle size, illustrated in Figure 5. The result shows that the heat value of the oxidation reaction decreased abruptly $(3.4$ to $1.6 \mathrm{~kJ} / \mathrm{g}$ ) due to an increase of nZVI particle size from 40 to 50 nanometers. Then, the amount of heat remained constant. The ultra-small $\mathrm{Fe}^{0}$ particle size might sorb facile oxygen moieties while the larger particles limited the heat transfer activity between the $\mathrm{Fe}^{0}$ and the oxygen. Therefore, the quantity of heat reaction varies considerably as a function of the particle size. 


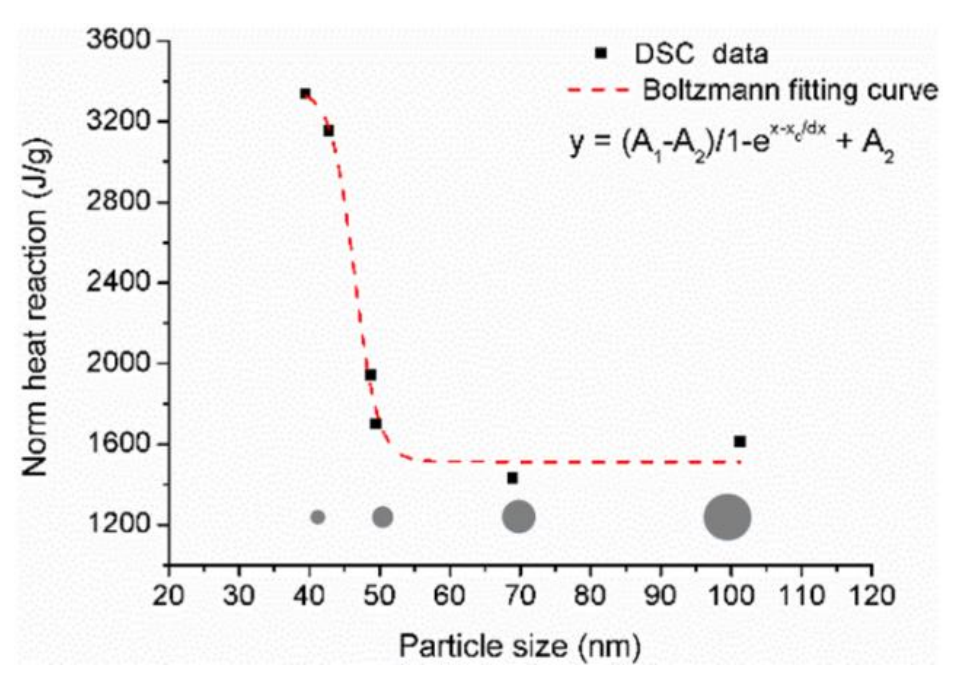

Figure 5. The plot of normalized heat of oxidation reaction $(\mathrm{J} / \mathrm{g})$ in a function of particle size for synthesized nZVI powder sample obtained using ethanol and diethyl ether

It should be noted that heat conduction in nanoscale may diverge notably from the Fourier's law prediction concerning the scatter of its boundary and interface as well as the limited relaxation time of heat carriers [10]. The Boltzmann equation for transportation of the electron, neutron, and photon is chiefly applied for nanostructures and heat transfer configurations [10,31]. In this study, the oxidation heat (q), which depended on the nanoscale size of nZVI particles (x), see in Figure 5, was well fitted using the Boltzmann equation (Equation 6).

$$
q=A_{2}+\frac{A_{1}-A_{2}}{1-e^{\frac{x-x_{c}}{d x}}}
$$

The Boltzmann function displayed a sigmoidal curve where the critical nZVI particle size ( $\mathrm{x}_{c}$ ) was $46.8 \mathrm{~nm}$. The Boltzmann's constant, $A_{l}$ and $A_{2}$, yielded 3,355.27 J/g and 1,513.52 J/g, respectively.

\section{Conclusions}

The present study shows that nanoscale zero-valent iron can be achieved by the chemical reduction method. A selection of suitable solvent plays a significant role as an oxidation protector - the use of ethanol and diethyl ether enables to stabilize the formation of nanoscale $\mathrm{Fe}^{0}$ core. The addition of the optimized amount of DI water to such solvents affected a proper distribution of nZVI particles. The prepared nZVI particle formed a spherical shape with a cubic structure. TEM and XRD analysis detected the iron oxide $\left(\mathrm{Fe}_{2} \mathrm{O}_{3}\right)$ phase, which displays as a shell covering the $\mathrm{Fe}^{0}$ core. The technique of TGA/DSC can help us to comprehend a thorough knowledge of the nZVI thermal oxidation reaction. The nZVI particle sizes influence the heat transfer, mainly conduction mode, and consequently release a definite quantity of the heat of oxidation reaction. Controlling particle size in a suitable range for different applications should be suggested since the heat release depends upon particle size. A result of the size-dependent heat release was well predicted using Boltzmann's equation. 


\section{Acknowledgment}

This study was funded by the fiscal year's project for the undergraduate program in chemical engineering (Engineering faculty) and by the Research Unit of Developing Technology and Innovation of Alternative Energy for Industries, Burapha University. The authors would like to acknowledge Mr. Punyapat Korop, and Mr. Nakarin Pingkason for their laboratory helps. Moreover, the authors would like to state their appreciation to Mrs. Warunya Junhom for her support in thermal analysis.

\section{Nomenclatures}

$$
\begin{aligned}
& \mathrm{SSA}=\text { Specific surface area, } \mathrm{m}^{2} / \mathrm{g} \\
& \rho_{\mathrm{th}}=\text { Theoretical density of zero-valent iron, } 7.847 \mathrm{~g} / \mathrm{cm}^{3} \\
& \mathrm{~d}_{\mathrm{TEM}}=\text { Particle diameter measured by TEM instrument, } \mathrm{nm} \\
& \Delta \mathrm{H}=\text { Enthalpy change of reaction, } \mathrm{J} / \mathrm{g} \\
& \mathrm{q}=\text { Specific heat of reaction, } \mathrm{J} / \mathrm{g} \\
& \mathrm{C}_{\mathrm{p}}=\text { Heat capacity at constant pressure, } \mathrm{J} / \mathrm{g} . \mathrm{K} \\
& \Delta \mathrm{T}=\text { Change in temperature, } \mathrm{K} \\
& \mathrm{x}=\text { Particle size, } \mathrm{nm} \\
& \mathrm{x}_{\mathrm{c}}=\text { Critical particle size, } \mathrm{nm} \\
& A_{1}, A_{2}=\text { Boltzmann's constant, } \mathrm{J} / \mathrm{g} \\
& \mathrm{dx}=\text { Difference in particle size, } \mathrm{nm}
\end{aligned}
$$

\section{References}

[1] J.D. Torrey, J.P. Killgore, N.M. Bedford, and L.F. Greenlee, "Oxidation behavior of zero-valent iron nanoparticles in mixed matrix water purification membranes," Environmental Science: Water Research \& Technology, Vol. 1, No. 2, pp. 146-152, 2015.

[2] X. Chen, D. Ji, X. Wang, and L. Zang, "Review on nano zerovalent iron (nZVI): From modification to environmental applications," IOP Conference Series: Earth and Environmental Science, Vol. 51, p. 012004, 2017.

[3] R. Mandal, A. Baranwal, A. Srivastava, and P. Chandra, "Evolving trends in bio/chemical sensor fabrication incorporating bimetallic nanoparticles," Biosensors and Bioelectronics, Vol. 117, pp. 546-561, 2018.

[4] D. Aman, A.A. Alkahlawy, and T. Zaki, "Hydrolysis of $\mathrm{NaBH}_{4}$ using $\mathrm{ZVI} / \mathrm{Fe}_{2}\left(\mathrm{MoO}_{4}\right)_{3}$ nanocatalyst," International Journal of Hydrogen Energy, Vol. 43, No. 39, pp. 18289-18295, 2018.

[5] S.A. Messele, O.S.G.P. Soares, C. Bengoa, F. Stüber, A. Fortuny, A. Fabregat, and J. Font, "Effect of activated carbon surface chemistry on the activity of ZVI/AC catalysts for fenton-like oxidation of phenol," Catalysis Today, Vol. 240, pp. 73-79, 2015.

[6] Z. Foltynowicz, A. Bardenshtein, S. Sangerlaub, H. Antvorskov, and W. Kozak, "Nanoscale, zero valent iron particles for application as oxygen scavenger in food packaging," Food Packaging and Shelf Life, Vol. 11, pp. 74-83, 2017. 
[7] S. Oropeza, M. Corea, C. Gómez-Yáñez, J.J. Cruz-Rivera, and M.E. Navarro-Clemente, "Zero-valent iron nanoparticles preparation," Materials Research Bulletin, Vol. 47, No. 6, pp. 1478-1485, 2012.

[8] R. Yuvakkumar, V. Elango, V. Rajendran, and N. Kannan, "Preperation and characterisation of zero valent iron nanoparticles," Digest Journal of Nanomaterials and Biostructures, Vol. 6, No. 4, pp. 1771-1776, 2011.

[9] M.I. Alymov, N.M. Rubtsov, B.S. Seplyarskii, V.A. Zelenskii, and A.B. Ankudinov, "Preparation and characterization of iron nanoparticles protected by an oxide film," Inorganic Materials, Vol. 53, No. 9, pp. 911-915, 2017.

[10] R. Yang, G. Chen, M. Laroche, and Y. Taur, "Simulation of nanoscale multidimensional transient heat conduction problems using ballistic-diffusive equations and phonon boltzmann equation," Journal of Heat Transfer, Vol. 127, No. 3, pp. 298-306, 2005.

[11] K. Fujita, D. Ando, M. Uchikoshi, K. Mimura, and M. Isshiki, "New model for lowtemperature oxidation of copper single crystal," Applied Surface Science, Vol. 276, pp. 347$358,2013$.

[12] M. Lenglet, K. Kartouni, J. Machefert, J.M. Claude, P. Steinmetz, E. Beauprez, J. Heinrich, and N. Celati, "Low temperature oxidation of copper: The formation of CuO," Materials Research Bulletin, Vol. 30, No. 4, pp. 393-403, 1995.

[13] V. Sarathy, P.G. Tratnyek, J.T. Nurmi, D.R. Baer, J.E. Amonette, C.L. Chun, R.L. Penn, and E.J. Reardon, "Aging of iron nanoparticles in aqueous solution: Effects on structure and reactivity," The Journal of Physical Chemistry C, Vol. 112, No. 7, pp. 2286-2293, 2008.

[14] L.F. Greenlee, J.D. Torrey, R.L. Amaro, and J.M. Shaw, "Kinetics of zero valent iron nanoparticle oxidation in oxygenated water," Environmental Science \& Technology, Vol. 46, No. 23, pp. 12913-12920, 2012.

[15] J. Adusei-Gyamfi and V. Acha, "Carriers for nano zerovalent iron (nZVI): Synthesis, application and efficiency," RSC Advances, Vol. 6, No. 93, pp. 91025-91044, 2016.

[16] C. Wang, D.R. Baer, J.E. Amonette, M.H. Engelhard, J. Antony, and Y. Qiang, "Morphology and electronic structure of the oxide shell on the surface of iron nanoparticles," Journal of the American Chemical Society, Vol. 131, No. 25, pp. 8824-8832, 2009.

[17] N. Arancibia-Miranda, S.E. Baltazar, A. García, A.H. Romero, M.A. Rubio, and D. Altbir, "Lead removal by nano-scale zero valent iron: Surface analysis and $\mathrm{pH}$ effect," Materials Research Bulletin, Vol. 59, pp. 341-348, 2014.

[18] L. Chekli, B. Bayatsarmadi, R. Sekine, B. Sarkar, A. Maoz Shen, K.G. Scheckel, W. Skinner, R. Naidu, H.K. Shon, E. Lombi, and E.Donner, "Analytical characterisation of nanoscale zerovalent iron: A methodological review," Analytica Chimica Acta, Vol. 903, pp. 13-35, 2016.

[19] S. Machado, J. G. Pacheco, H. P. A. Nouws, J. T. Albergaria, and C. Delerue-Matos, "Characterization of green zero-valent iron nanoparticles produced with tree leaf extracts," Science of The Total Environment, Vol. 533, pp. 76-81, 2015.

[20] T. Shahwan, T. Shahwan, S. Abu Sirriah, M. Nairat, E. Boyaci, A.E. Eroğlu, T.B. Scott, and K.R.Hallam, "Green synthesis of iron nanoparticles and their application as a fenton-like catalyst for the degradation of aqueous cationic and anionic dyes," Chemical Engineering Journal, Vol. 172, No. 1, pp. 258-266, 2011.

[21] S. Sangami and B. Manu, "Synthesis of green iron nanoparticles using laterite and their application as a fenton-like catalyst for the degradation of herbicide Ametryn in water," Environmental Technology \& Innovation, Vol. 8, pp. 150-163, 2017. 
[22] Y. El Mendili, J.-F. Bardeau, N. Randrianantoandro, F. Grasset, and J.-M. Greneche, "Insights into the mechanism related to the phase transition from $\gamma-\mathrm{Fe}_{2} \mathrm{O}_{3}$ to $\alpha-\mathrm{Fe}_{2} \mathrm{O}_{3}$ nanoparticles induced by thermal treatment and laser irradiation," The Journal of Physical Chemistry C, Vol. 116, No. 44, pp. 23785-23792, 2012.

[23] S. Nasrazadani, "The application of infrared spectroscopy to a study of phosphoric and tannic acids interactions with magnetite $\left(\mathrm{Fe}_{3} \mathrm{O}_{4}\right)$, goethite $(\alpha-\mathrm{FeOOH})$ and lepidocrocite $(\gamma-\mathrm{FeOOH})$, Corrosion Science, Vol. 39, No. 10, pp. 1845-1859, 1997.

[24] F.J. Ewing, "The crystal structure of lepidocrocite," The Journal of Chemical Physics, Vol. 3, p. 420, 1935.

[25] A. Bumajdad, S. Ali, and A. Mathew, "Characterization of iron hydroxide/oxide nanoparticles prepared in microemulsions stabilized with cationic/non-ionic surfactant mixtures," Journal of Colloid and Interface Science, Vol. 355, No. 2, pp. 282-292, 2011.

[26] D. Li, X. Hu, Y. Sun, S. Su, A. Xia, and H. Ge, "Goethite ( $\alpha-\mathrm{FeOOH})$ nanopowders synthesized via a surfactant-assisted hydrothermal method: Morphology, magnetic properties and conversion to rice-like $\alpha-\mathrm{Fe}_{2} \mathrm{O}_{3}$ after annealing," RSC Advances, Vol. 5, No. 34, pp. 2709127096, 2015.

[27] D.H. Huang, T.N. Tran, and B. Yang, "Investigation on the reaction of iron powder mixture as a portable heat source for thermoelectric power generators," Journal of Thermal Analysis and Calorimetry, Vol. 116, No. 2, pp. 1047-1053, 2014.

[28] A.J. Habish, S. Lazarević, I. Janković-Častvan, B. Jokić, J. Kovač, J. Rogan, Đ. Janaćković, and R. Petrović, "Nanoscale zerovalent iron (nZVI) supported by natural and acid-activated sepiolites: The effect of the nZVI/support ratio on the composite properties and $\mathrm{Cd}^{2+}$ adsorption," Environmental Science and Pollution Research, Vol. 24, No. 1, pp. 628-643, 2017.

[29] M. Krajewski, M. Krajewski, K. Brzozka, W.S. Lin, H.M. Lin, M. Tokarczyk, J. Borysiuk, G. Kowalski, and D. Wasik, "High temperature oxidation of iron-iron oxide core-shell nanowires composed of iron nanoparticles," Physical Chemistry Chemical Physics, Vol. 18, No. 5, pp. 3900-3909, 2016.

[30] D. Wen, P. Song, K. Zhang, and J. Qian, “Thermal oxidation of iron nanoparticles and its implication for chemical-looping combustion," Journal of Chemical Technology \& Biotechnology, Vol. 86, No. 3, pp. 375-380, 2011.

[31] A.J.T.C.R. Tellier, Size Effects in Thin Films, $1^{\text {st }}$ Edition, Elsevier, Amsterdam, 1982. 